\title{
Environmental correlates of activity and energetics in a wide-ranging social carnivore
}

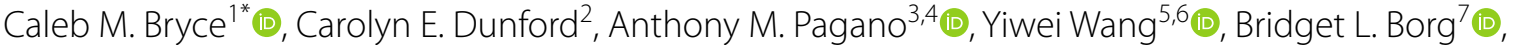 \\ Stephen M. Arthur ${ }^{7,8}$ and Terrie M. Williams ${ }^{1}$ (1)
}

\begin{abstract}
Background: Environmental conditions can influence animal movements, determining when and how much animals move. Yet few studies have quantified how abiotic environmental factors (e.g., ambient temperature, snow depth, precipitation) may affect the activity patterns and metabolic demands of wide-ranging large predators. We demonstrate the utility of accelerometers in combination with more traditional GPS telemetry to measure energy expenditure, ranging patterns, and movement ecology of 5 gray wolves (Canis lupus), a wide-ranging social carnivore, from spring through autumn 2015 in interior Alaska, USA.
\end{abstract}

Results: Wolves exhibited substantial variability in home range size (range $500-8300 \mathrm{~km}^{2}$ ) that was not correlated with daily energy expenditure. Mean daily energy expenditure and travel distance were $22 \mathrm{MJ}$ and $18 \mathrm{~km}^{\text {day }}{ }^{-1}$, respectively. Wolves spent $20 \%$ and $17 \%$ more energy during the summer pup rearing and autumn recruitment seasons than the spring breeding season, respectively, regardless of pack reproductive status. Wolves were predominantly crepuscular but during the night spent $2.4 \times$ more time engaged in high energy activities (such as running) during the pup rearing season than the breeding season.

Conclusion: Integrating accelerometry with GPS telemetry can reveal detailed insights into the activity and energetics of wide-ranging predators. Heavy precipitation, deep snow, and high ambient temperatures each reduced wolf mobility, suggesting that abiotic conditions can impact wolf movement decisions. Identifying such patterns is an important step toward evaluating the influence of environmental factors on the space use and energy allocation in carnivores with ecosystem-wide cascading effects, particularly under changing climatic conditions.

Keywords: Alaska, Behavior, Canis lupus, Carnivore, Ecology, Energetics, Movement

\section{Background}

Wildlife movement decisions while foraging are driven by a dynamic balance between maximizing energy intake and minimizing costs. In addition to foraging and prey availability, wildlife movements are influenced by

\footnotetext{
${ }^{*}$ Correspondence: calebmbryce@gmail.com

${ }^{1}$ Department of Ecology and Evolutionary Biology, University

of California-Santa Cruz, Coastal Biology Building, 130 McAllister Way, Santa Cruz, CA 95060, USA

Full list of author information is available at the end of the article
}

competition, predators, reproductive demands, and abiotic factors. As the currency of ecosystem function, energetic demand influences the behavioral decisions animals make, dictating, where and how often they feed [1-4]. Mammalian apex carnivores in particular experience intrinsically elevated energy demands associated with large body size [5], endothermy [6] and carnivory [7, 8]. To replenish the energy expended on vital functions (e.g., metabolic work and activity, thermoregulation, growth, reproduction, repair, waste; [9-11]), predators must locate, capture, and kill mobile prey. Hunting itself is an original author(s) and the source, provide a link to the Creative Commons licence, and indicate if changes were made. The images or other third party material in this article are included in the article's Creative Commons licence, unless indicated otherwise in a credit line to the material. If material is not included in the article's Creative Commons licence and your intended use is not permitted by statutory regulation or exceeds the permitted use, you will need to obtain permission directly from the copyright holder. To view a copy of this licence, visit http://creativecommons.org/licenses/by/4.0/. The Creative Commons Public Domain Dedication waiver (http://creativeco mmons.org/publicdomain/zero/1.0/) applies to the data made available in this article, unless otherwise stated in a credit line to the data. 
energetically demanding activity with potential cascading impacts across the ecological community [12]. Hunting decisions of top predators and movement pathways may trigger both density and behaviorally mediated trophic cascades by directly decreasing prey populations and indirectly impacting the behavior of herbivores [13-16] and sympatric mesopredators [17-21]. Given the global decline in many top predator species [22-24], the quantification of free-ranging behaviors and resulting energy demands is integral for defining resource requirements and understanding how movement patterns of these species might propagate through the food web [25-29].

As cursorial predators, gray wolves (Canis lupus) expend immense energy resources in finding, pursuing, and capturing prey [30]. To obtain prey and maintain territories, wolves roam widely on a daily basis [31], often utilizing natural and anthropogenic linear travel corridors where available [32-35]. In some cases, wolves have been observed chasing prey for over $20 \mathrm{~km} \mathrm{[36]} \mathrm{and}$ covering nearly $80 \mathrm{~km}$ in $12 \mathrm{~h}$ [37]. Thus, in optimizing movement and hunting success, wolves are affected by both abiotic (e.g., temperature, snow depth, precipitation) and biotic (e.g., prey movement and vulnerability, proximity of rival packs) factors [38-42]. Given that climate change is rapidly warming northern latitudes and impacting not only ambient temperature [e.g., 41] but also the timing, type and location of precipitation [44, 45], it is especially important to understand how wolves currently respond to these variables.

While numerous studies have estimated wolf energy intake (energy gain via consumption of prey; [46-48]), few have quantified energy expenditure of free-ranging wolves, particularly at hourly scales across multiple seasons. Continuous metabolic demands of free-ranging animals are inherently difficult to estimate [49], but sophisticated biologgers can now provide detailed insights into how wolves adjust their movements and energy expenditure in response to environmental and seasonal factors. Daily energy requirements may be particularly high for breeders (reproductive adults that are socially dominant given their size, behavior, and interactions with pack mates \& rival packs [50-52]). As pack leaders, breeders often assume energy-demanding functions such as initiating prey attacks and breaking trail through high vegetation or deep snow [50, 53, 54]. Despite the crucial role that dominant wolves play in pack persistence [55-57], free-ranging activity patterns and associated energy budgets for these animals remain poorly understood [58].

Here, we describe an 8-month (March to October) analysis of wolf movement in interior Alaska using information collected by combined tri-axial accelerometerGPS radiocollars (hereafter ACC-GPS collars) deployed on free-ranging male wolves. By calibrating these ACCGPS data on captive wolves and utilizing published estimates of wolf movement energetics (i.e., measures of oxygen consumption $[59,60])$, we compared daily energy expenditure (DEE) estimated via accelerometry with DEE derived from relationships between oxygen consumption and animal speed (determined using GPS telemetry location data). We accounted for the potential effects of topography on both measures of DEE by measuring the slope angle at which wolves travelled [61]. In addition, we estimated the movement rates $\left(\mathrm{m} \mathrm{h}^{-1}\right)$ and home range size $\left(\mathrm{km}^{2}\right)$ of these individuals to evaluate whether they served as reliable proxies for energy expenditure and to make ecological inferences about the movement patterns of their packs.

We tested whether abiotic environmental variables, including ambient temperature, snow depth, and precipitation affected the movement rates of wolves and their energy expenditure at hourly, daily, and seasonal temporal scales. We defined seasons based on the known breeding cycle of wolves in interior Alaska: breeding (March-April), pup-rearing (May-July), and pup recruitment (August-October). Given the wide-ranging movements of this apex predator $[8,58,62]$, we expected that wolves would reduce movement rates during physiologically suboptimal conditions (e.g., being active in ambient temperatures beyond the species' thermoneutral zone), with analogous DEE levels. We predicted that deeper snow and higher temperatures, but not greater precipitation, would reduce wolf movement rates and DEE. We further examined whether these relationships varied seasonally. Finally, we discuss ecological insights gained by our efforts to quantify activity patterns and energy expenditure of these predators.

\section{Results}

Behavior calibrations from nine captive wolves (Fig. 1) resulted in clearly defined ODBA threshold values for each behavior (Additional file 4: Fig. S1). From this, we defined five ODBA behavioral categories to use for wolves in the wild as: $<0.1 \mathrm{~g}$ (resting), $0.1<0.25 \mathrm{~g}$ (stationary), $0.25<0.75 \mathrm{~g}$ (walking), $0.75<1 \mathrm{~g}$ (highly active), and $>=1 \mathrm{~g}$ (running). We calculated the proportion of time each wolf spent conducting these behaviors.

Data were collected from four adult (ages 2-3 years) male wolves (body mass $45.9 \pm 1.4 \mathrm{~kg}$ ) in Denali National Park and Preserve (DNPP, Alaska, USA) via ACC-GPS collars from March through October 2015 (208-211 days wolf ${ }^{-1}$; Table 1). Data were additionally collected from one male wolf (age 2 years, body mass $45 \mathrm{~kg}$ ) that was monitored from March until it was killed adjacent to DNPP in early May (50 days); our results, therefore, describe a total of 887 wolf-days. Collared individuals 

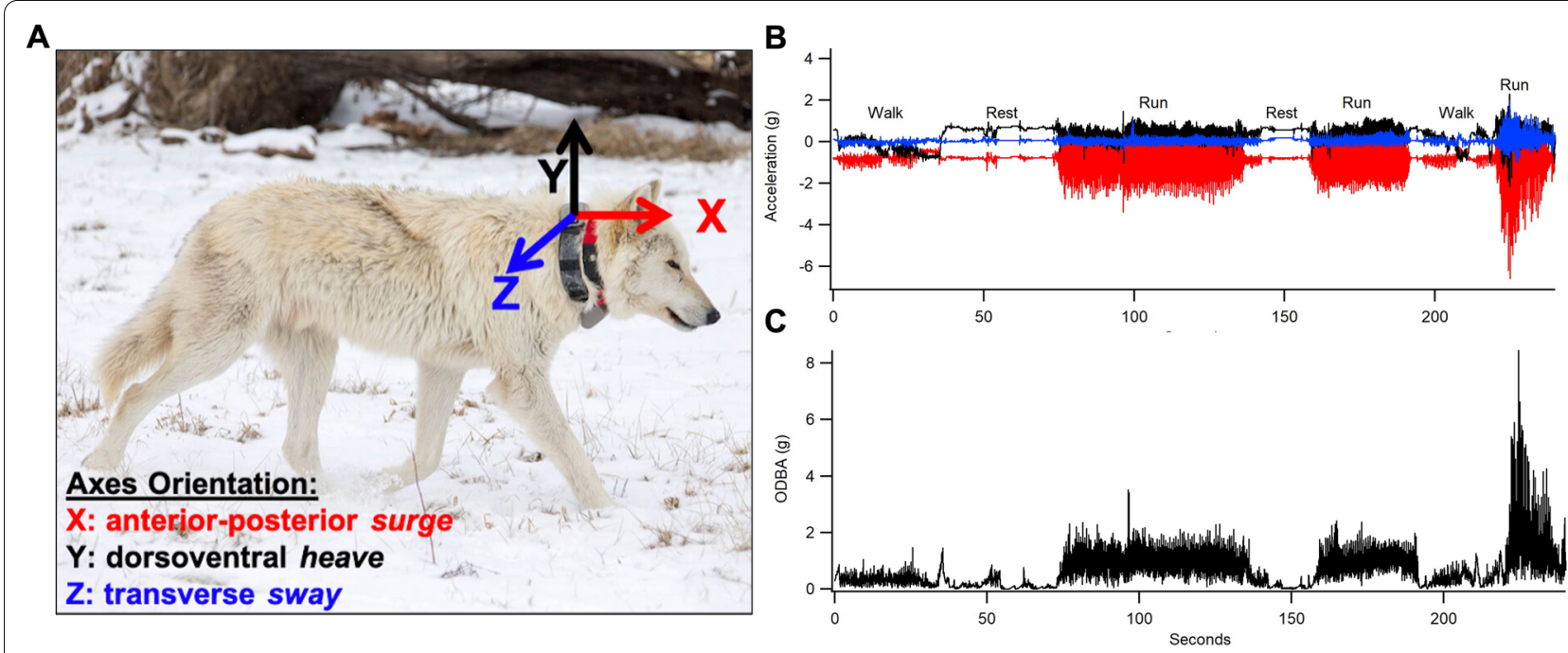

Fig. 1 Wolf accelerometer-GPS collar calibration, showing $\mathbf{A}$ axis orientation, $\mathbf{B}$ a 4-min raw data sample depicting how distinct behaviors generate unique collar accelerometer signatures, and $\mathbf{C}$ associated overall dynamic body acceleration (ODBA) values

were dominant wolves (known or suspected breeders) in packs ranging in size from 2 to 14 individuals $(5.4 \pm 2.2$ wolves/pack). Over the deployment period, home ranges (95\% utilization distributions (UD)) ranged from 510 to $8258 \mathrm{~km}^{2}$ with the largest UD used by the wolf in the western portion of the study area (Table 1, Fig. 2A). Terrain heterogeneity is high in DNPP, so we measured the elevations utilized (Fig. 2B) and slope angles of wolf paths (Additional file 5: Fig. S2) to account for the additional energy demands of navigating through mountainous terrain (see Methods). The median slope angle travelled by all wolves was level $\left(-0.07^{\circ} \pm 0.04\right.$; Additional file 5 : Fig. S2). The steepest uphill slope the wolves selected was $35.6^{\circ}$ and the steepest downhill slope observed was $-53.5^{\circ}$. Wolves used a mean slope angle of $1.9^{\circ} \pm 0.1$, and slope angle varied among individuals $(F=384.98, \mathrm{df}=4$, $p<0.001, R^{2}=0.29$ ).

\section{Daily energy expenditure}

Mean $\left( \pm\right.$ SE) wolf DEE was $21.8 \pm 0.2 \mathrm{MJ}^{-1}$ day $^{-1}$ (range: 9.9-50.3 MJ day ${ }^{-1}$; Table 1) when estimated from overall dynamic body acceleration (ODBA). Mean DEE estimated from ODBA was not significantly correlated with home range size (95\% UDs, $r^{2}=-0.26, p=0.70, n=5$ ), but was significantly correlated with daily distance traveled $\left(r^{2}=0.83, P=0.02, n=5\right.$; Table 1$)$ based on linear regression. We tested the significance of linear mixed effects models using chi-square tests and conditional $R^{2}$ and we calculated estimated marginal means (EMMs) to test for pairwise differences between seasons. DEE varied among seasons $\left(x^{2}=57.18, \mathrm{df}=2, p<0.001, R^{2}=0.56\right.$;
Fig. 3) and was significantly lower during the breeding season than in the pup rearing season $(\mathrm{EMMs} p<0.05)$ but not the recruitment season (EMMs $P=0.31$ ). There was no difference between the pup rearing and recruitment seasons (EMMs $P=0.96$ ). DEE calculated using ODBA varied among individuals $(F=76.89, \mathrm{df}=4$, $p<0.001, R^{2}=0.26$; Table 1).

When calculated using continuous time correlated random walk (CTCRW) model-derived speed from the GPS location data (see Methods), the mean DEE was $15.8 \pm 0.1 \mathrm{MJ}$ day $^{-1}$ (range: 9.5-31.0 MJ day ${ }^{-1}$ ). This DEE estimate differed significantly from the mean DEE estimated from ODBA (Wilcoxon sign ranked test; $V=2093, P<0.001)$. Mean CTCRW-derived DEE was not significantly correlated with home range size $(95 \%$ UDs, $\left.r^{2}=-0.28, P=0.75, n=5\right)$ or daily distance traveled $\left(r^{2}=0.65, P=0.06, n=5\right.$; Table 1$)$ based on linear regression. On average, the CTCRW movement-derived DEE was $6 \mathrm{MJ}^{\text {day }^{-1}}$ (95\% CI 5.7-6.3) less than the DEE estimated from ODBA. The CTCRW movementderived DEE varied among individuals $(F=141.98, \mathrm{df}=4$, $p<0.001, R^{2}=0.39$; Table 1). CTCRW movement-derived DEE also varied among seasons $\left(x^{2}=19.08, \mathrm{df}=2\right.$, $p<0.001, R^{2}=0.74$, Fig. $3 \mathrm{~B}$ ) and was marginally lower during the breeding season compared to the pup rearing (EMMs $p=0.076$ ) but there was no statistical difference when compared to the recruitment season (EMMs $p=0.99)$ or between the pup rearing and recruitment season (EMMs $p=0.56$ ). 


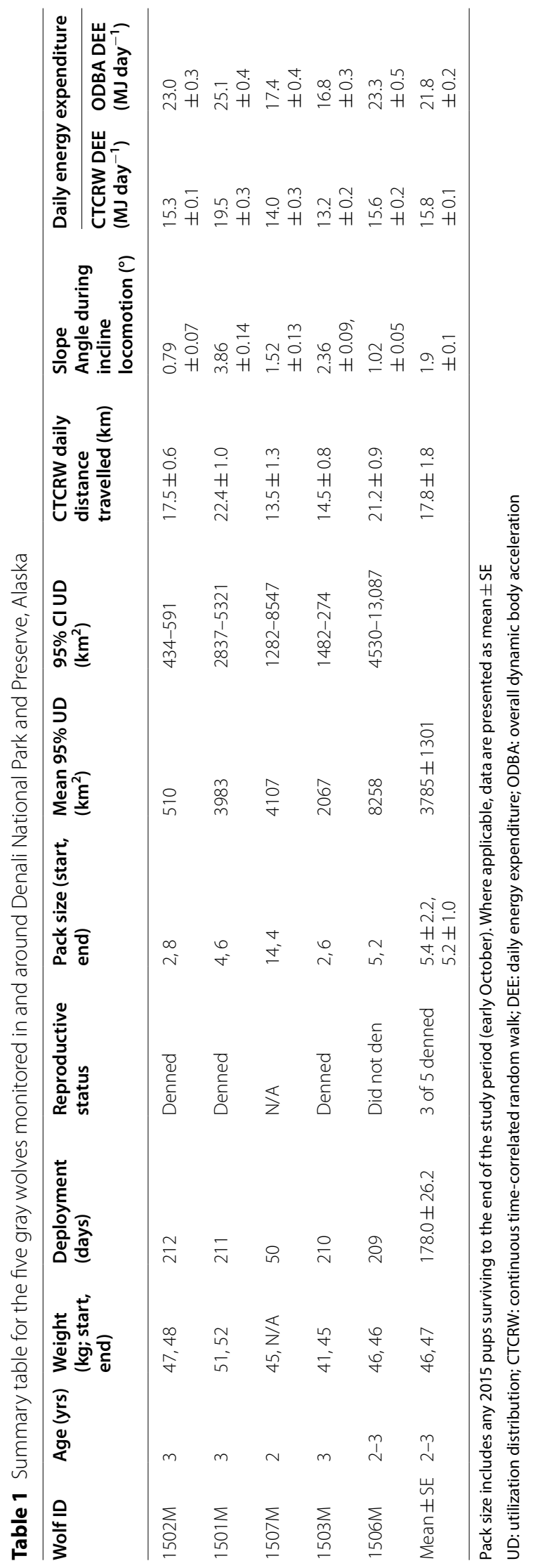


A

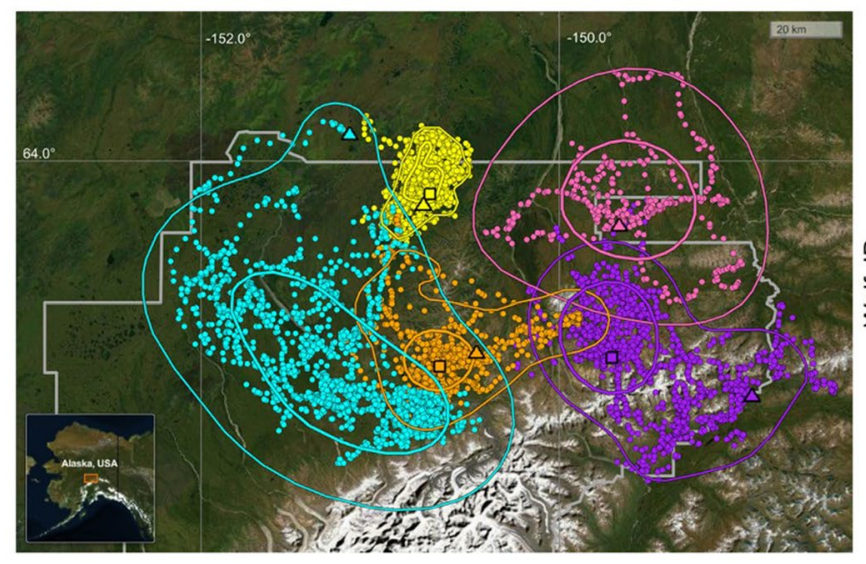

B

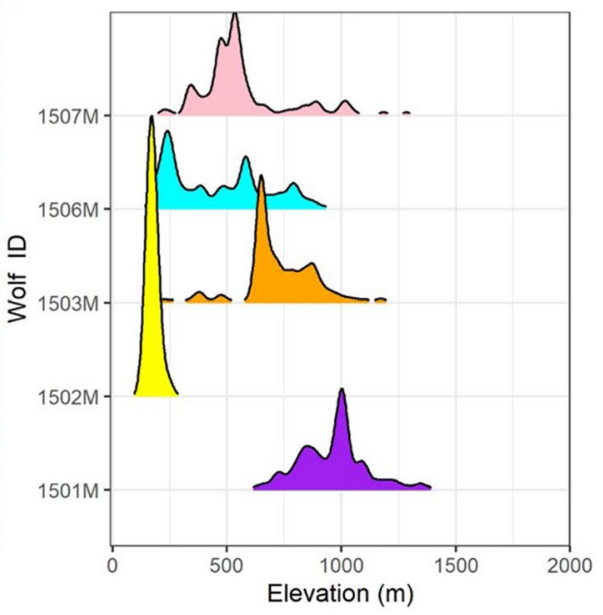

Fig. 2 Study area depicting (A) accelerometer-GPS instrumented male wolf $(n=5)$ hourly relocations (colored points), core area (50\% autocorrelated kernel density estimate (AKDE) utilization distribution; thick, inner colored contour) and home range (95\% AKDE utilization distribution; thin, outer colored contour) in Denali National Park and Preserve, Alaska from March to October 2015. Triangles correspond to capture locations; squares depict den sites $(n=3)$. B The frequency at which each wolf used the elevations within their range. Colors correspond with the map colors for wolf ID. Minimum elevation: 141.14 m (ID: 1502 M), maximum elevation: 1848.81 m (ID: 1501 M)

The ODBA and CTCRW movement-derived DEE were correlated $\left(r^{2}=0.71, p<0.001, n=869\right)$ and increased linearly by the equation:

$$
\begin{aligned}
& \text { CTCRW movement - derived DEE } \\
& \quad=5.43+0.48 * \text { ODBA DEE }
\end{aligned}
$$

as shown in Additional file 6: Fig. S3.

\section{Seasonal effects on wolf activity and movement}

Averaged across seasons, wolves travelled $17.8 \mathrm{~km} \mathrm{day}^{-1}\left( \pm 1.8 \mathrm{~km} \mathrm{day}^{-1}\right)$. During the breeding season, wolves travelled on average $16.7 \pm 0.9 \mathrm{~km} \mathrm{day}^{-1}$ (range: $14.7-19.6 \mathrm{~km} \mathrm{day}^{-1}$ ). In the pup rearing season, they travelled on average $21.0 \pm 0.7 \mathrm{~km} \mathrm{day}^{-1}$ (range: 9.4-23.8 $\mathrm{km} \mathrm{day}^{-1}$ ), and during the recruitment season wolves travelled on average $18.3 \pm 0.7 \mathrm{~km}^{\text {day }}{ }^{-1}$ (range: $7.9-23.9 \mathrm{~km} \mathrm{day}^{-1}$ ). In doing so, wolves maintained expansive but variable home ranges (mean: $3785 \pm 1300 \mathrm{~km}^{-1}$, Table 1) with considerably smaller core areas of use (50\% UDs, mean: $875 \pm 301 \mathrm{~km}^{-1}$; Fig. 2A).

We found a seasonal effect on wolf activity (mean hourly ODBA; Fig. 4A). Mean hourly ODBA varied with season $\left(\mathrm{X}^{2}=226.41, \mathrm{df}=2, p<0.001, R^{2}=0.77\right)$ and was $38 \%$ and $27 \%$ higher during the pup rearing and recruitment seasons than the breeding season
(EMMs $p<0.001$ and EMMSs $p=0.084$, respectively). In contrast, movement rates did not vary seasonally. Movement rates were $644 \pm 15 \mathrm{~m} \mathrm{~h}^{-1}, 876 \pm 15 \mathrm{~m} \mathrm{~h}^{-1}$, and $764 \pm 16 \mathrm{~m} \mathrm{~h}^{-1}$ for the breeding, pup rearing, and recruitment seasons, respectively (EMMs $p=0.007-$ $0.99)$. Hourly movement rates and hourly ODBA were positively correlated $\left(R^{2}=0.40, p<0.001\right)$.

\section{Environmental factors affecting wolf activity and movement rate \\ Temperature}

An interaction between ambient temperature and season affected wolf mean hourly ODBA $\left(x^{2}=350.84\right.$, $\left.\mathrm{df}=2, p<0.001, R^{2}=0.51\right)$ and hourly movement rate $\left(\mathrm{X}^{2}=293.98, \mathrm{df}=2, p<0.001, R^{2}=0.64\right)$. Mean hourly ODBA increased marginally with increasing temperature in the breeding season (slope $(\beta)=0.006, t=4.6$, $p<0.001)$ but decreased with increasing temperature during pup rearing $(\beta=-0.04, t=-18.6, p<0.001)$ and recruitment $(\beta=-0.02, t=-7.4, p<0.001$; Fig. $5 \mathrm{~A})$. Wolf hourly movement rate increased marginally with increasing temperatures during the breeding season $(\beta=4.5, t=2.4, p=0.02)$ but decreased with increasing temperatures during pup rearing $(\beta=-53.6, t=-17.1$, $p<0.001)$ and recruitment $(\beta=-22.6, t=3.9, p<0.001)$ (Fig. 5B). 


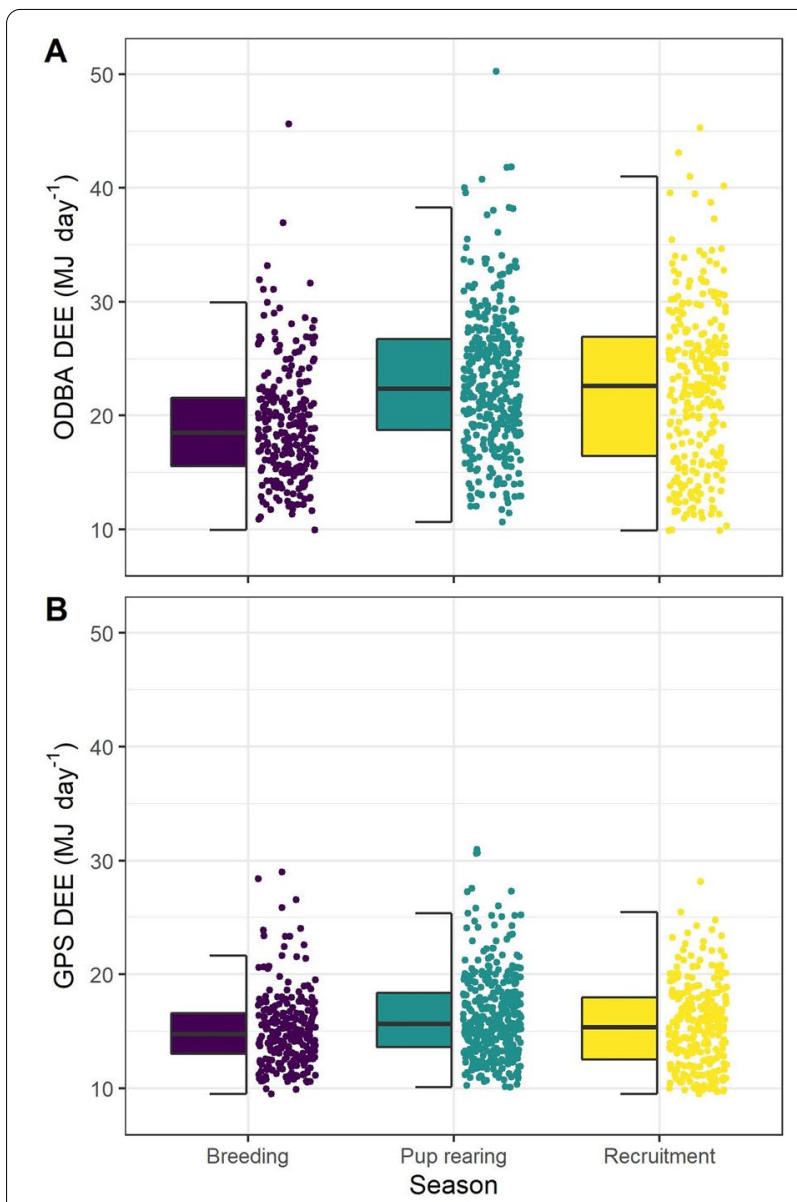

Fig. 3 Daily energy expenditure (DEE, MJ day ${ }^{-1}$ ) of male wolves $(n=5)$ in Denali National Park and Preserve, Alaska across 3 wolf biological seasons (breeding, pup-rearing, and recruitment), calculated from $\mathbf{A}$ Eqn. S1 using overall dynamic body acceleration (ODBA) derived from tri-axial accelerometers and $\mathbf{B}$ Eqn. S4 using speed derived from hourly continuous time-correlated random walk (CTCRW) derived coordinates. Within each box, horizontal black lines denote median values; boxes extend from the 25th to the 75th percentile of each group's distribution of values; vertical extending lines denote adjacent values within 1.5 interquartile range of the 25 th and 75 th percentile of each group

\section{Snow depth}

Snow depth also affected wolves' mean hourly ODBA with an interaction with season $\left(X^{2}=23.31, \mathrm{df}=2\right.$, $p<0.001, R^{2}=0.53$ ). Wolf ODBA was reduced with increasing snow depth during the breeding season (when the snow was deepest during our study) $(\beta=-0.008$, $t=-6.6, p<0.001)$. In the pup rearing and recruitment seasons when the snow depth did not exceed $28 \mathrm{~cm}$, wolf ODBA was not affected by snow depth (Fig. 5C). Similarly, there was an interaction between snow depth and season affecting wolf hourly movement rate $\left(\chi^{2}=32.87\right.$, $\left.\mathrm{df}=2, p<0.001, R^{2}=0.65\right)$, where the wolves reduced movements with increased snow depth during the breeding season $(\beta=-0.17, t=-5.7, p<0.001)$. Movements did not appear to be affected by snow depth in the pup rearing and recruitment seasons as little to no snow was present (Fig. 5D).

\section{Precipitation-rain and snowfall}

We found an interactive effect between hourly precipitation and season on the mean hourly ODBA of wolves $\left(x^{2}=6.45, \mathrm{df}=2, p=0.04, R^{2}=0.74\right)$. High levels of precipitation reduced ODBA during the pup rearing season $(\beta=-0.05, t=-2.5, p=0.01)$, whereas ODBA was not significantly affected by hourly precipitation in the breeding or recruitment seasons (when precipitation was less; Fig. 5E). In contrast, hourly movement rates were unaffected by hourly precipitation $\left(\mathrm{X}^{2}=1.06, \mathrm{df}=1, p=0.30\right.$, $R^{2}=0.60$; Fig. $5 \mathrm{~F}$ ), and there was no interaction between season and precipitation $\left(\mathrm{x}^{2}=2.86, \mathrm{df}=2, p=0.24\right.$, $\left.R^{2}=0.60\right)$.

\section{Daily patterns in activity}

Mean hourly ODBA varied with hour of the day $(0-23)$ in all seasons, and diel activity patterns also differed among seasons (Fig. 4b; see Additional file 2: Table S1 for GAMM results). Irrespective of season, the wolves exhibited crepuscular activity patterns in both mean hourly ODBA and movement rates. On average, they moved at higher rates at dusk (defined as $1 \mathrm{~h}$ before to $1 \mathrm{~h}$ after sunset, mean: $1072 \pm 33 \mathrm{~m} \mathrm{~h}^{-1}$, breeding: $941 \pm 58$; pup rearing: $1208 \pm 55$; recruitment: $1009 \pm 60$ ) and dawn (defined as $1 \mathrm{~h}$ before to $1 \mathrm{~h}$ after sunrise, mean: $1073 \pm 37 \mathrm{~m} \mathrm{~h}^{-1}$, breeding: $810 \pm 61$; pup rearing: $1371 \pm 62$; recruitment: $909 \pm 66)$. Wolves moved at lower rates during the day (673 $\pm 11 \mathrm{~m} \mathrm{~h}^{-1}$ : breeding: $606 \pm 20 \mathrm{~m} \mathrm{~h}^{-1}$; pup rearing: $733 \pm 17 \mathrm{~m} \mathrm{~h}^{-1}$; recruitment: $\left.619 \pm 21 \mathrm{~m} \mathrm{~h}^{-1}\right)$ and at night ( $831 \pm 18 \mathrm{~m} \mathrm{~h}^{-1}$ : breeding: $586 \pm 25$; pup rearing: $1174 \pm 49$; recruitment: $890 \pm 29$ ).

Wolves were least active during the day in all seasons, predominantly crepuscular during the breeding season, and most active at night during the pup rearing and recruitment seasons. These differences in the time of day the wolves were active each season matches the proportion of time the wolves spent with high or low ODBA in each hour (Fig. 4). Fine-scale measurements of movements from the ACC show that the wolves spent the majority of each hour resting in the breeding season $(68.1 \% \pm 0.4$, totaling $16 \mathrm{~h}$ and $20 \mathrm{~min}$ of the day) and only $5.7 \% \pm 0.1$ ( $1 \mathrm{~h}$ and $22 \mathrm{~min}$ each day) running (ODBA > 1 g; Additional file 7: Fig. S4). In contrast, during the pup rearing and recruitment seasons, wolves spent over two hours running each day $(9.3 \% \pm 0.2$ and 

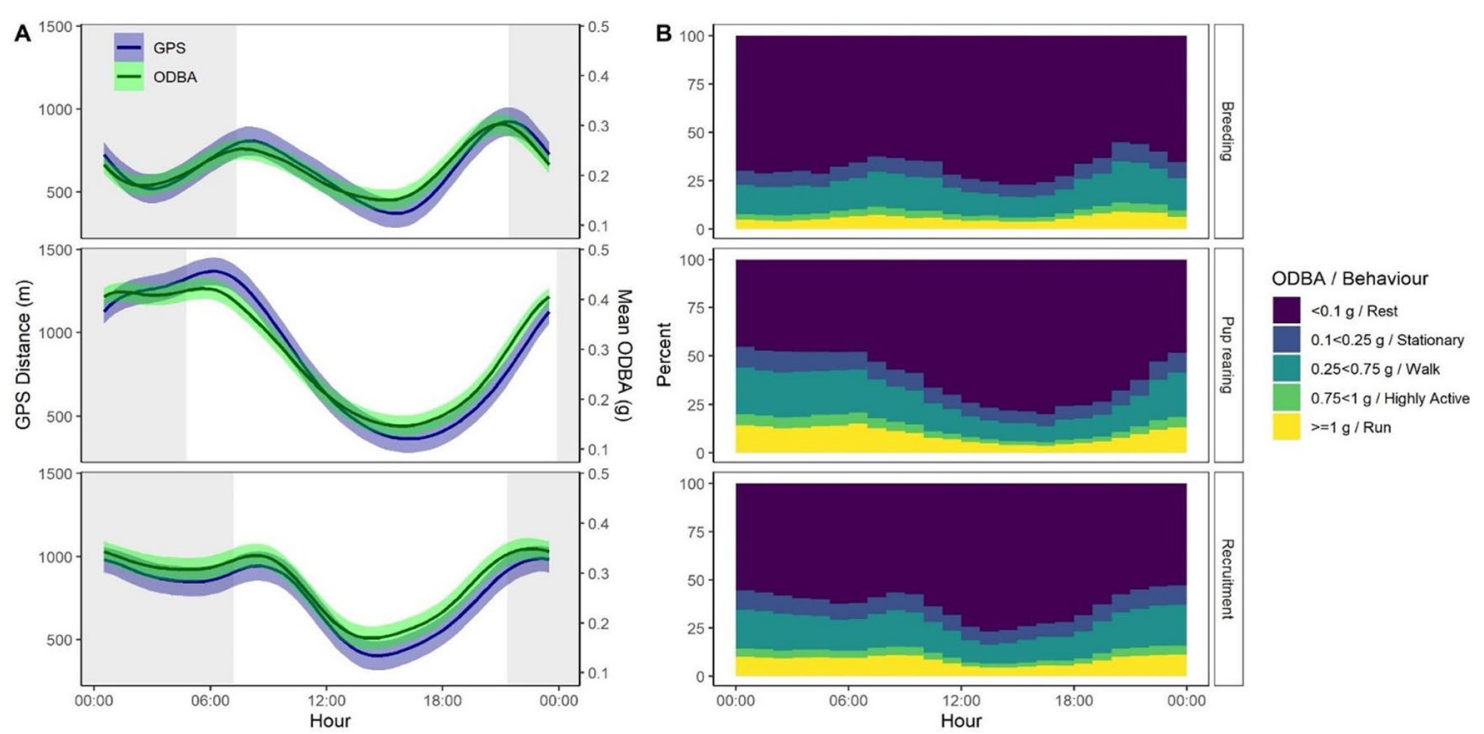

Fig. 4 Daily activity patterns of male wolves $(n=5)$ in Denali National Park and Preserve, Alaska in three biological seasons: breeding, pup-rearing, and recruitment. A GAM smoothing of the distance moved between successive 1-h continuous time-correlated random walk (CTCRW) derived locations (blue line, $\mathrm{m}$ ), and the mean hourly overall dynamic body acceleration (ODBA, green line, $g$ ), as a function of hour of day (both with standard error shading). Day (white) and night (shaded) are indicated based on the average sunrise and sunset times for each season during collaring. Note the separate axis on the right for ODBA. B The proportion of each hour of the day when the ODBA (g) was within specific levels (see ODBA/Behavior scale) for each of the observed seasons. High ODBA are in yellow colors, low ODBA are in dark blues

$8.4 \% \pm 0.2$, respectively) while spending $63 \%$ of the day resting (Table 2).

During the night, wolves spent $2.4 \times$ more time running during the pup rearing season than the breeding season. During the pup rearing season, wolves spent $1.6 \times$ more time running during the night than in the day. The distribution of high ODBA activities between night and day was more consistent during the breeding and recruitment seasons, but wolves were consistently less active in the breeding season compared to other seasons (Fig. 3, Table 2).

Similar to ODBA, wolf hourly movement rate varied with hour of the day in all seasons (Additional file 3: Table S2) and wolves moved the shortest distances during the day. Movement patterns were predominantly crepuscular in the breeding season and nocturnal in the pup rearing and recruitment seasons (Fig. 4a).

\section{Discussion}

We quantified the movement ecology of wolves equipped with ACC-GPS collars to estimate DEE and infer how several environmental factors (temperature, snow depth, precipitation) and topography affect the behavior of these wide-ranging carnivores in non-winter conditions. Wolves were primarily crepuscular (Fig. 4), were less active in high ambient temperatures, and largely unaffected by all but the heaviest precipitation (Fig. 5). Regardless of whether the pack was reproductively successful, collared wolves were more active in the pup-rearing and recruitment seasons (Fig. 3) than in the spring breeding season.

We found wolves exhibited varying responses in activity due to ambient temperature. During the breeding season, which was the coldest season of our study (mean: $-3.4{ }^{\circ} \mathrm{C} \pm 0.1$, range: $-35.4-11 .{ }^{\circ} \mathrm{C}$ ), activity rates marginally increased with temperature. During the pup rearing season, which was the warmest season of our study (mean: $11.5{ }^{\circ} \mathrm{C} \pm 0.1$, range: $-1.1-29.9{ }^{\circ} \mathrm{C}$ ), activity rates decreased with increasing temperatures. Similarly, during the recruitment season (mean: $5.7{ }^{\circ} \mathrm{C} \pm 0.1$, range: $-9.7-22.8{ }^{\circ} \mathrm{C}$ ) activity rates decreased with increasing temperatures. Based on these findings, high ambient temperatures appeared to have the strongest impacts on activity rates. These results are similar to other cursorial canids including dingoes (Canis dingo) [63] and African wild dogs (Lycaon pictus) [64] that exhibited declines in activity rates with increasing ambient temperatures. Wolves are coldadapted $[31,65,66]$ but have higher maintenance costs (i.e., elevated basal metabolic rates) associated with large organ masses to thermoregulate in the cold [67-69], which would not be accounted for in either of our measures of DEE [70]. The hottest observed temperatures occurred during the day in the pup rearing season, and while this 

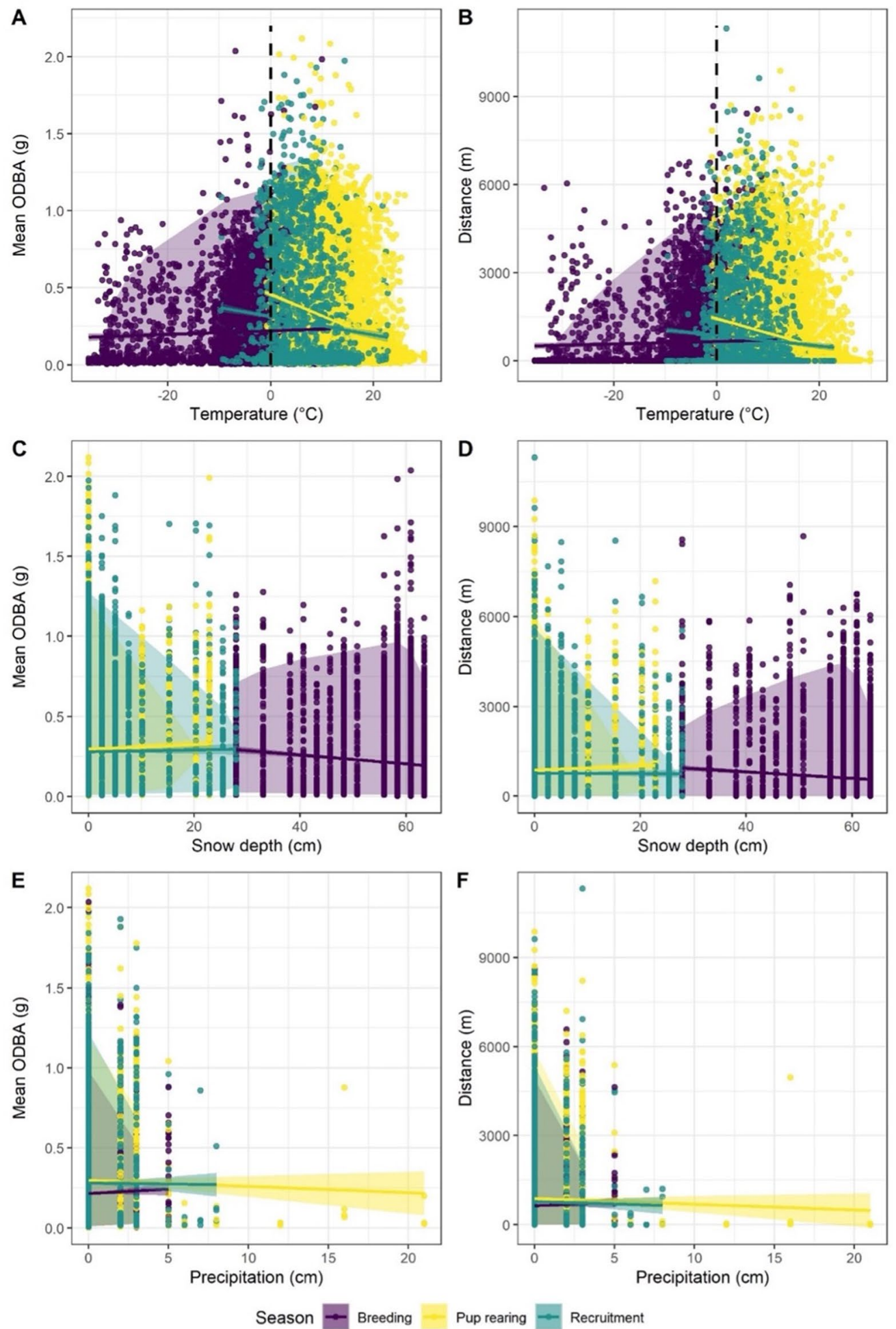

Fig. 5 Scatter plots of mean hourly overall dynamic body acceleration (ODBA ( $\mathrm{g}$ ), left panels) and hourly movement rate ( $\mathrm{m} \mathrm{h}^{-1}$, right panels) for male wolves $(n=5)$ in Denali National Park and Preserve, Alaska as a function of ambient temperature $\left({ }^{\circ} \mathrm{C}, \mathbf{A}, \mathbf{B}\right.$; dashed line denotes $\left.0{ }^{\circ} \mathrm{C}\right)$, snow depth $(\mathrm{cm}, \mathbf{C}, \mathbf{D})$, and precipitation ( $\mathrm{cm}, \mathbf{E}, \mathbf{F})$. Colors correspond to wolf biological seasons and shading encompass $95 \%$ of the data 
Table 2 Seasonal \% of hour running and resting averaged across 5 adult male wolves in Denali National Park and Preserve, Alaska

\begin{tabular}{|c|c|c|c|c|}
\hline \multirow[t]{2}{*}{ Season } & \multicolumn{3}{|c|}{ Running (\% of hour) } & \multirow{2}{*}{$\begin{array}{l}\text { Resting (\% of } \\
\text { hour) } \\
\text { Whole day }\end{array}$} \\
\hline & Day & Night & Whole day & \\
\hline Breeding & $5.84 \pm 0.16$ & $5.42 \pm 0.19$ & $5.66 \pm 0.12$ & $68.06 \pm 0.44$ \\
\hline Pup rearing & $8.29 \pm 0.16$ & $13.22 \pm 0.35$ & $9.31 \pm 0.15$ & $61.73 \pm 0.39$ \\
\hline Recruitment & $7.37 \pm 0.21$ & $9.91 \pm 0.27$ & $8.42 \pm 0.17$ & $63.16 \pm 0.45$ \\
\hline
\end{tabular}

For wolves, running corresponds to overall dynamic body acceleration $(\mathrm{ODBA})>1 \mathrm{~g}$, while resting corresponds to ODBA $<0.1 \mathrm{~g}$ (see Additional file 5: Fig. S2; mean $\pm \mathrm{SE}$ )

was the most active season overall, wolves were most mobile at dusk and dawn rather than during the heat of the day. Similarly, moose (Alces alces) and caribou (Rangifer tarandus), wolves' primary prey in DNPP, are also heatsensitive [72-76]. Behavioral plasticity may be key for mitigating adverse effects of increasing diurnal temperatures in wolves and other wide-ranging predators $[77,78]$.

Snow was only present during the first and last few weeks of our study (absent from May 5 until Sept. 15; [79]). The presence and depth of snow can influence both prey movements and their habitat selection $[80,81]$ as well as the energetic costs of wolf movement [82]. Snow can be an impediment to movement in heavier-bodied herbivore prey due to higher foot loading $[39,83]$, yet wolves were also less active and had lower movements during periods of deeper spring snow in the study area (Fig. 5C, D). Wolves selectively travel through shallow, supportive snow in natural conditions, although their ability to behaviorally mitigate the energetic costs imposed by snow are limited [84]. No significant multi-decadal trend in annual snowfall at the park headquarters exists, but the winter snowfall leading into our study (i.e., 2014-2015) was lighter than normal [85] and our spring results may, therefore, be representative of the increasingly mild conditions predicted with arctic climate change.

Wolf activity, but not distance travelled, was affected by an hourly precipitation-season interaction. Winter snowfall has been shown to temporarily reduce wolf activity as it is thought to dampen hunting success [82]. As spring progressed into summer pup-rearing, wolves were less active during the instances of heavy rain that occurred. These inverse effects across seasons suggest that all but the most extreme precipitation is unlikely to significantly affect wolf movements.

For highly mobile animals such as wolves, habitat structure and metabolic transport costs are inextricably linked. Heterogeneity in the external environment (including slope, vegetation, substrate type) influences animal movement costs [86-88], and in turn these movement costs impact how animals move through and interact with their environment [89-91]. Some DNPP wolf home ranges encompass mountainous terrain in the Alaska Range and underscore the impact of the surrounding environment on modulating transit costs. For example, wolf $1501 \mathrm{M}$ routinely traversed high alpine passes $(>2000 \mathrm{~m})$, while traveling between dens located on both sides of the range crest (Fig. 2). He consequently traversed the steepest average slopes of all the packs at $3.9^{\circ}$ (compared to $0.8-2.4^{\circ}$ for other packs) and averaged the farthest movements (Table 1). As a result, wolf $1501 \mathrm{M}$ had the highest associated DEE. Using an approach we established with pumas (Puma concolor) [61], our DEE analysis explicitly incorporates the additional metabolic cost associated with locomotion up a slope in wolves traversing mountainous terrain. Topographic slope has been shown to strongly influence large carnivore habitat selection and movement patterns at fine temporal scales [91-93]. Optimizing use of energy stores (e.g., via least-cost route selection [94]) may be critical for these species, which experience higher absolute and relative net transport costs for uphill locomotion and less downhill 'reimbursement' than lighter animals $[95,96]$.

As with other animals, wolf movement ecology is driven by seasonally variable internal and external factors including hunger, fear, and habitat $[66,97,98]$. Our study's aim was to quantify wolf behavioral and energetic responses to environmental conditions, but nearby ungulate prey also respond to these same conditions simultaneously. Given that measuring prey activity was beyond the scope of the study, it is difficult to differentiate whether wolves were responding dynamically to the activities of their prey, or directly to the environment. The size of the study area and the associated heterogeneity in local conditions also constrain our scope of inference. We sourced hourly temperature, precipitation, and snow depth from a single central weather station, but these parameters are inherently variable in mountainous terrain, and data from one central site does not necessarily reflect true conditions at the location of the wolves. In addition, we collected data exclusively from dominant adult males within a pack ("breeders") who likely exhibit higher movement-related energy demands relative to other members of the pack $[50,53,54]$.

Across individuals and seasons, the average wolf massspecific DEE (454 $\mathrm{kJ} \mathrm{kg}^{-1} \mathrm{~d}^{-1}$; Table 1) is comparable to a 
previously reported wolf field metabolic rate (FMR, $474 \mathrm{~kJ}$ $\mathrm{kg}^{-1} \mathrm{~d}^{-1}$; [99]) derived using the doubly labelled water method, and energy requirement estimates based on food consumption (473-715 kJ kg $\mathrm{kg}^{-1}$; $\left.[46,58,65]\right)$. The DEE we derived may differ from prior estimates of wolf energy requirements via methodological or ecological variation. Rather than measuring FMR over several days to weeks via doubly labelled water or estimating it by a multiple of basal metabolic rate, we used equivalent travel speeds to link mass-specific wolf oxygen consumption measurements to collar-derived ODBA values from wild conspecifics. However, unlike doubly labelled water, our method for measuring DEE only accounts for changes in movement-related costs and cannot account for changes in energy expenditure resulting from thermoregulation, reproduction, growth, specific dynamic action, or basal metabolic rate [70]. The accelerometer-equipped wolves we monitored were highly mobile and active for an average of $36 \%$ or $8.6 \mathrm{~h}$ of each day (Table 2), comparable to previous estimates $[100,101]$. Metabolic requirements for wolves are approximately $25 \%$ higher than a typical eutherian mammal of similar body mass [102], suggesting that to survive, wolves must consume considerably more calories than would be predicted based on their body mass. This elevated cost of carnivory translates into disproportionately high resource requirements [8].

Our analyses focused on quantifying wolf activity patterns and energy expenditure (rather than energy intake via prey consumption as well) in part due to the remoteness of the study area. The largely snow-free collar deployment duration coupled with the outlying locations of DNPP pack territories precluded our ability to field-verify wolf kill remains from GPS clusters. However, field studies capable of investigating even a small number of GPS clusters stand to benefit from using accelerometry in combination with GPS telemetry to detect kill sites to estimate kill rates (and, therefore, energy intake) for wolves. Preliminary assessments of this multi-sensor approach were recently demonstrated for wolves and other terrestrial carnivores in a captive setting [103], and the technique may prove to be critical in estimating kill rates in remote sites, such as Denali, where field-verifying GPS clusters may be logistically challenging, cost prohibitive, or both. The combination of energetic intake and expenditure could then be used to inform physiological landscape models of animal movement (e.g., [104, 105]).

When comparing accelerometer and movementderived metrics to estimate DEE in wild wolves, the two measures were strongly correlated $\left(R^{2}=0.71\right)$, but ODBA estimates averaged $1.4 \times$ greater than those obtained from GPS fixes (Table 1). This difference is linked to the distinct sampling intervals of the two sensors: accelerometers took near-continuous measurements, while we relied on hourly GPS fixes to prolong collar battery life. In addition to movements that result in changes in location, accelerometers are able to measure all body movement costs (e.g., scratching, interacting with conspecifics) regardless of changes in animal location [70]. Our results suggest that DEE was substantially impacted by body movements that were not captured by changes in hourly locations. GPS location fixes have a spatial accuracy of $\leq 31 \mathrm{~m}$ [106], which may have also introduced some error in our movement-derived DEE. Infrequent location-derived measures of DEE inherently underestimate animal movement paths, and, therefore, energy expenditure, and should be considered conservative $[28,107]$. In addition, we found home range size poorly predicted mean DEE, which suggests that home range size alone may not serve as a reliable proxy for energy expenditure. Yet, mean daily distance travelled did strongly correlate with mean ODBA-derived DEE, suggesting that point-topoint movements were important determinants of energy expenditure in the individuals we monitored.

Once properly calibrated, accelerometers can provide fine-scale documentation of animal behavior [108] and DEE $[49,109]$, as evidenced here through activity budgets of wild wolves across multiple seasons. While we averaged our accelerometer data over hourly intervals to evaluate abiotic determinants of wolf DEE, high-frequency accelerometer data can also be used to evaluate instantaneous energetic costs, such as measuring the costs of individual kill events of prey $[28,110]$ and escape responses to disturbance $[111,112]$. Our study monitored largely snow-free conditions for wolves, so additional studies are needed to reveal fine-scale wolf behavior and energy budgets in response to snow throughout the course of the winter when it presents more of an impediment to movement, although some recent work has been conducted [82, 84]. Future studies are also warranted to examine thermal effects on fine-scale wolf activity throughout winter, when temperatures are considerably colder than what we observed [71].

\section{Conclusion}

Our study demonstrates the capacity of integrating accelerometry with GPS telemetry to reveal activity and energetic insights from carnivores in unprecedented detail. Such analyses offer a mechanistic approach for evaluating wolf travel patterns and resource requirements. As northern latitudes continue to rapidly warm and change, the application of these methods to future studies would enable researchers to track how fluctuations in parameters including snowfall patterns and plant phenology and growth cascade up to impact the spatial ecology and energetics of predators [113, 114]. In lower latitudes, recovering gray wolf populations in the USA have recently been delisted from protection under 
the Endangered Species Act of 1973 [115]. Given the loss of federal protection, insight into wolf foraging patterns and prey requirements obtained via multi-sensor telemetry may be invaluable for informing regionally specific management decisions and promoting the persistence of this keystone species throughout its range.

\section{Methods}

\section{Data collection}

\section{Wolf collar calibration}

We utilized a lab-to-field approach in which the routine behaviors and locomotor biomechanics of captive wolves ( $n=9$ adults, 4 male, 5 female; mass $=37.6 \mathrm{~kg} \pm 0.7 \mathrm{SE}$ ) instrumented with ACC-GPS collars; model GPS Plus, Vectronic Aerospace, Germany; approx. 960 g) were measured in large ( $>1$ acre) outdoor enclosures prior to deployment on free-ranging conspecifics in the wild (Fig. 1). ACC-GPS collars sampled acceleration continuously at $32 \mathrm{~Hz}$ ( $\pm 8 \mathrm{~g}$ range) and took hourly GPS location fixes. We paired video-recorded (Sony HDR-CX290/B, $1080 \mathrm{HD}, 60 \mathrm{p})$ observations of captive wolves engaged in routine activities with collar accelerometer measurements to construct behavior and energy budgets for free-ranging conspecifics. Five wolf behavioral categories were identified for the purpose of this study: rest, stationary, walk, highly active, and run. Behaviors and ODBA, a widely used proxy for animal energy expenditure [109, 116], were measured as each wolf was filmed moving freely at known speeds behind a vehicle and along a fence line between trainers in outdoor enclosures. Both speed and metabolic rate are tightly linked to the dynamic component of an animal's body acceleration [109, 117, 118], which allowed us to use wolf ODBA to translate sensor output from the collars into travel speed and the metabolic demands of various activities in the wild.

We estimated the increase in DEE due to topography by measuring the slopes travelled by wolves from the change in elevation between consecutive location coordinates (see Additional file 1). Following Dunford et al. [61], we then modelled the metabolic cost of travel on slopes from previous studies of wolf energetics measured via open-flow respirometry on level and inclined treadmills. Oxygen consumption $\left(\dot{V} \mathrm{O}_{2}\right)$ of wolves on the level was measured by Taylor et al. [59], and $\dot{V} \mathrm{O}_{2}$ of wolves moving on slopes up to $14^{\circ}$ was provided by Weibel et al. [60]. The increased energetic cost of travel up a slope was, therefore, calculated as

$$
\begin{aligned}
& \dot{V} \mathrm{O}_{2} \text { deg. incline }{ }^{-1}=0.00743+0.028 \\
& \quad * \text { Speed }\left(n=5, R^{2}=0.98, p<0.001\right) .
\end{aligned}
$$

where speed is in $\mathrm{m} \mathrm{s}^{-1}$ and $\dot{V} \mathrm{O}_{2}$ is in $\mathrm{ml} \mathrm{O}_{2} \mathrm{~kg}^{-1} \mathrm{~min}^{-1}$. Decline (slope $<0^{\circ}$ ) costs were modeled as level given that energy expenditure associated with downhill travel can be either more or less costly than level costs depending on the down-slope angle travelled $[95,119,120]$.

\section{Wolf monitoring}

In March 2015, male gray wolves were captured in the northern portion of DNPP (see Additional file 1; Fig. 2A) using aerial darting by helicopter [121] and anesthetized with zolazepam-tiletamine $\left(\right.$ Telazol $^{\circledR}$, Fort Dodge Laboratories, Fort Dodge, IA, USA). Once anesthetized, wolves were weighed, measured, and fitted with the same ACC-GPS collars used during behavioral calibration with captive wolves. We selected free-ranging adult male wolves that were dominant (i.e., known or suspected to be breeders) so our results would not be confounded by sex or age-related variation in space use and energetics.

To address seasonal patterns of movement and energy expenditure, we parsed the March-October collar deployment window into seasons based on the known breeding cycle of wolves in interior Alaska. These were defined as breeding (February-April), pup-rearing (MayJuly), pup recruitment (August-October), and nomadic (November-January; [57]). Our March to October data collection, therefore, includes insights into all but the nomadic winter movements of wolves in interior Alaska, which have been studied extensively (e.g., [62, 122]).

Collars recorded GPS locations hourly, and data were downloaded directly from the collars upon retrieval. During our 8-month study window, wolves were visually observed from single-engine airplanes on 13 monitoring flights to validate current wolf locations, wolf pack size and composition, active den site locations and use, breeding status of individual wolves, and the timing and suspected causes of mortality. ACC-GPS collars were removed at the conclusion of this study.

\section{Environmental variables}

All environmental variables were recorded at the Kantishna automated Snow Telemetry (SNOTEL) site (63.53845, -150.98365, elevation: 509 m; https://wcc.sc. egov.usda.gov/nwcc/site?sitenum $=1072$ ). This station was selected because it is located near the geographic center the study area, and therefore, its data may be representative of general trends throughout the study area on the north slope of the Alaska Range. However, it may not reflect conditions at the locations of each wolf. The Kantishna SNOTEL site has a year-round precipitation gauge that measures snow and rain along with a meteorological station that records air temperature and other weather parameters. Data were recorded and transmitted from Kantishna hourly. These data were exported for the study duration, converted to metric units, and utilized in subsequent analyses. Additional details on the 
measurement of environmental variables are provided in the Additional file 1.

\section{Wolf movement modelling}

Wolf collars averaged a successful fix rate of $99.7 \%$ $( \pm 0.08 \%)$, but to account for missing or irregularly timed location data, we used a continuous time-correlated random walk (CTCRW) model (R package 'crawl' [123, 124]) to predict locations on hourly intervals based on the GPS locations. We derived utilization distributions from the CTCRW locations using the full deployment period of each wolf. We measured the area of the utilization distribution using 95\% (home range) and 50\% (core area) of the autocorrelated kernel density estimation (AKDE) method in the R package 'ctmm' [125]. Speeds of freeranging wolves were calculated as the distance between consecutive CTCRW fixes using the Haversine formula divided by the elapsed time. Speed was further calculated using ODBA from the accelerometers (Eqn. S3). This resulted in two different estimates of slope-informed energy expenditure for the wolves (Eqn. S1, Eqn., S4). In both cases, the $\dot{V} \mathrm{O}_{2}$ was converted to an hourly wholebody field energetic cost (in kilojoules) by multiplying by $20.1 \mathrm{~J} \mathrm{ml}^{-1}$, by each individual wolf's mass (in kg; [126]), and by 60 (for energy expenditure per hour). Hourly energy expenditures were summed to give DEE (in MJ). These DEE measurements including slope-corrected locomotion costs are used throughout the paper. Any days with less than $20 \mathrm{~h}$ of ODBA data were excluded in the DEE estimates $(n=6)$.

\section{Statistics}

All analyses were conducted in the R statistical software [127]. All Chi-square, $F$, and $p$ values were obtained using the Anova function from the 'car' package [128] and conditional $R^{2}$ from the R package 'MuMIn' [129]. Response and explanatory variables of all models described below are summarized in Additional file 3: Table S2.

The $l m$ function, from the base functions in $R$, was used to fit a linear model (LM) with DEE (calculated using ODBA) as the dependent variable and wolf ID as the independent variable to test for individual differences. We fit the same LM with DEE (calculated using CTCRW movement rate) as the dependent variable. We also tested the strength and direction of the correlation between the CTCRW movement-derived DEE and ODBA DEE using Pearson's correlation. In addition, we tested for correlations between home range size and mean daily distance traveled with both measures of mean DEE for each wolf using linear regression to evaluate the ability of home range size and movement to serve as proxies for energy expenditure. We tested for normality in the CTCRW movement-derived DEE and ODBA DEE using Shapiro-Wilk tests and the data were determined to be not normally distributed. Therefore, we used a nonparametric Wilcoxon signed-rank test for paired samples to quantify whether the CTCRW movement-derived DEE differed significantly from the ODBA derived DEE. Finally, we used the $l m$ function to assess whether the path angles the wolves travelled on varied between individuals. Path angle was transformed using the natural logarithm.

To examine the effect of season on DEE of wolves, we constructed 2 linear mixed effects models (LMM, via the lmer function in the 'lme4' package [130]) with either ODBA or the CTCRW movement-derived DEE as the dependent variable and biological season and wolf ID as the independent variables, with the season and wolf ID as nested random variables to account for repeated measures per individual and allow variable intercepts and slopes for season. The function emmeans (from the 'emmeans' package [131]) was used to calculate EMMs and test for pairwise differences between seasons for each model.

Mean hourly ODBA was taken as the mean of ODBA across each hour, transformed for normal Gaussian distribution using Ordered Quantile normalization (via the 'bestNormalize' R package [132]). We constructed an LMM with transformed hourly ODBA as the dependent variable and the season, and wolf ID as the independent variables, with wolf ID and season as nested random effects. The LMM was fitted with a Bound Optimization by Quadratic Approximation ('bobyqa') optimizer [133]. We also constructed this LMM model with CTCRWmeasured distance as the dependent variable. The function emmeans was used to test for pairwise differences between seasons for each model.

Similarly, to examine whether the wolves adjusted their activity level (mean hourly ODBA) in response to ambient air temperature, we generated a LMM with hourly ODBA as the dependent variable and ambient temperature, season, and wolf ID as explanatory variables, with an interaction between temperature and season. Wolf ID and season were included as nested random effects. Similarly, two further LMMs were constructed with the same dependent, independent, and random variables except temperature was replaced with either snow depth or precipitation. Finally, three additional LMMs with the same independent and random variables were constructed with the CTCRW-derived distances as the dependent variable. For the model of CTCRW distance by snow depth, CTCRW distance was square root transformed and a Nelder Mead optimizer was used. The two LMMs with precipitation as an independent variable were fitted with a Nelder Mead optimizer. 
To examine the daily activity patterns of wolves, we constructed generalized additive mixed models (GAMMs) using the R package 'mgcv' [134]. We set mean hourly ODBA (g) as a function of smoothed hour $(0-23)$ with an interaction with season. ID was included as a random variable. Models were fitted with a cyclic cubic regression spline and 20 knots. We also constructed the same model with CTCRW measured distance $(\mathrm{m})$ as the response variable rather than ODBA. All results are presented as mean \pm SE unless otherwise noted. We considered $p$ values $\leq 0.05$ as significant.

\section{Abbreviations}

ACC: Accelerometer; CTCRW: Continuous time-correlated random walk; DEE: Daily energy expenditure; DNPP: Denali National Park and Preserve; GPS: Global positioning system; ODBA: Overall dynamic body acceleration.

\section{Supplementary Information}

The online version contains supplementary material available at https://doi. org/10.1186/s40317-021-00272-w.

\section{Additional file 1. Supplementary methods}

Additional file 2: Table S1. Results of GAMMs of mean hourly ODBA and distance data analysis using Gaussian distribution with 'log' link. Estimates and standard errors are reported as decimal numbers, edf and degrees of freedom are reported in whole numbers.

Additional file 3: Table S2. Response and explanatory variables of models. ${ }^{* \prime}$ indicates inclusion of main effects and an interaction, ' + 'indicates inclusion of main effects with no interaction. Where nested variables were included, this is indicated as "|".

Additional file 4: Figure S1.Captive wolf ODBA (g) for rest and locomotion gaits.

Additional file 5: Figure S2. Density plot showing the speed wild wolves utilized for travelling (ODBA $>0.25 \mathrm{~g}$ ) relative to the selected topographical slope.

Additional file 6: Figure S3. The correlation between DEE derived from ODBA and CTCRW (i.e., GPS-derived) speed. Blue regression line (with standard error shading) is described by Eqn. 1, black regression line is line of isometry $(X=Y)$.

Additional file 7: Figure S4. Seasonal variation in \% of each hour associated with behaviors (binned by ODBA, g) for gray wolves in Denali National Park and Preserve, Alaska, USA.

\section{Acknowledgements}

We thank T. Cambier \& S. Hamilton for logistical support and for assistance with wild wolf capture in DNPP, as well as P. Goodmann \& D. Drenzek and the other helpful staff at Wolf Park (Battle Ground, IN) for allowing us to observe their captive wolves. We also thank J. Kamminga and members of the T.M. Williams lab for valuable initial discussions and feedback.

\section{Authors' contributions}

$\mathrm{CMB}$ and TMW conceived the ideas and designed methodology; $\mathrm{CMB}, \mathrm{BLB}$ and SMA collected the data; CED, AMP, and CMB analyzed the data; CMB and CED led the writing of the manuscript with assistance from YW and AMP. All authors contributed critically to the drafts and gave final approval for publication. All authors read and approved the final manuscript.

\section{Funding}

We received support for this project from the National Science Foundation (DBI-1255913, GK-12 DGE-0947923), Mazamas, the ARCS Foundation, and the University of California Santa Cruz Science Internship Program (SIP) and
Ecology and Evolutionary Biology (EEB) Department. Funding for wolf captures and monitoring flights was provided by the US National Park Service.

\section{Availability of data and materials}

The data sets generated and/or analyzed during for this study are available from the corresponding author upon reasonable request.

\section{Declarations}

\section{Ethics approval and consent to participate}

This study was conducted in strict accordance with animal ethics including capture and handling as approved by the United States Department of the Interior, National Park Service (Denali; Scientific Research and Collecting Permit \#DENA-2015-SCI-0001) and the University of California Santa Cruz Animal Care and Use Committee (IACUC Protocol \#Willt1504). All human interventions including capture, administration of immobilizing drugs, radio collaring, and monitoring were conducted to minimize negative/adverse impacts on the welfare of the wolves. In addition, Wolf Park approved the collaring and observation of their animals.

\section{Consent for publication}

Not applicable.

\section{Competing interests}

The authors declare that they have no competing interests.

\section{Author details}

${ }^{1}$ Department of Ecology and Evolutionary Biology, University of CaliforniaSanta Cruz, Coastal Biology Building, 130 McAllister Way, Santa Cruz, CA 95060, USA. ${ }^{2}$ School of Biological Sciences, Institute of Global Food Security, Queen's University of Belfast, 19 Chlorine Gardens, Belfast BT9 7DL, Northern Ireland, UK. ${ }^{3}$ San Diego Zoo Wildlife Alliance, San Diego, CA 92101, USA. ${ }^{4}$ Present Address: School of the Environment, Washington State University, Pullman, WA 99164, USA. ${ }^{5}$ San Francisco Bay Bird Observatory, 524 Valley Way, Milpitas, CA, USA. ${ }^{6}$ Center for Integrated Spatial Research, Environmental Studies Department, University of California, Santa Cruz, CA, USA. ${ }^{7}$ National Park Service, Denali National Park and Preserve, Central Alaska Inventory and Monitoring Network, P. O. Box 9, Denali Park, AK 99755, USA. ${ }^{8}$ U.S. Fish and Wildlife Service, Arctic National Wildlife Refuge, 101 12th Ave, Fairbanks, AK, USA.

Received: 17 August 2021 Accepted: 21 December 2021

Published online: 05 January 2022

\section{References}

1. Stephens DW, Krebs JR. Foraging theory. Princeton: Princeton University Press; 1986.

2. Brown JH, Gillooly JF, Allen AP, Savage VM, West GB. Toward a metabolic theory of ecology. Ecology. 2004;85:1771-89.

3. Speakman JR. The cost of living: Field metabolic rates of small mammals. Adv Ecol Res. Academic Press; 1999. p. 177-297. https://linki nghub.elsevier.com/retrieve/pii/S0065250408600197

4. Humphries MM, McCann KS. Metabolic ecology. J Anim Ecol. 2014;83:7-19.

5. Peters $\mathrm{RH}$. The ecological implications of body size. Cambridge: Cambridge University Press; 1983.

6. Bennett AF, Ruben JA. Endothermy and activity in vertebrates. Science. 1979;206:649-54.

7. Carbone C, Pettorelli N, Stephens PA. The bigger they come, the harder they fall: body size and prey abundance influence predator-prey ratios. Biol Lett. 2011;7:312-5.

8. Carbone C, Teacher A, Rowcliffe JM. The costs of carnivory. PLoS Biol. 2007;5:e22. https://doi.org/10.1371/journal.pbio.0050022.

9. Kleiber M. The fire of life: an introduction to animal energetics. New York: Wiley; 1961.

10. McNab BK. The significance of energetics for the population ecology of vertebrates. Physiol Ecol Vertebr a view from energ. Ithaca: Cornell University Press; 2002. p. 431-46. 
11. Withers PC, Cooper CE, Maloney SK, Bozinovic F, Cruz-Neto AP. Physiological characteristics of mammals. In: Withers PC, Cooper CE, Maloney SK, Bozinovic F, Cruz-Neto AP, editors. Ecol Environ Physiol Mamm. Oxford: Oxford University Press; 2016. p. 146-289.

12. Williams TM, Peter-Heide Jørgensen M, Pagano AM, Bryce CM. Hunters versus hunted: new perspectives on the energetic costs of survival at the top of the food chain. Funct Ecol. 2020;34:2015-29. https://doi.org/ 10.1111/1365-2435.13649.

13. Ripple WJ, Beschta RL. Wolves and the ecology of fear: can predation risk structure ecosystems? Bioscience. 2004;54:755-66.

14. Christianson D, Creel S. Ecosystem scale declines in elk recruitment and population growth with wolf colonization: a before-after-controlimpact approach. PLoS ONE. 2014;9:e102330.

15. Ripple WJ, Beschta RL, Painter LE. Trophic cascades from wolves to alders in Yellowstone. J Anim Ecol. 2015;354:254-60. https://doi.org/10. 1016/j.foreco.2015.06.007.

16. Creel S, Winnie J, Maxwell B, Hamlin K, Creel M, Winnie J, et al. Elk alter habitat selection as an antipredator responsen to wolves. Ecology. 2015;86:3387-97.

17. Prugh LR, Sivy KJ. Enemies with benefits: integrating positive and negative interactions among terrestrial carnivores. Sih A, editor. Ecol Lett. 2020;23:902-18. doi: https://doi.org/10.1111/ele.13489.

18. Levi T, Wilmers CC. Wolves-coyotes-foxes: a cascade among carnivores. Ecology. 2012;93:921-9.

19. Ripple WJ, Wirsing AJ, Wilmers CC, Letnic M. Widespread mesopredator effects after wolf extirpation. Biol Conserv. 2013;160:70-9.

20. Newsome TM, Ripple WJ. A continental scale trophic cascade from wolves through coyotes to foxes. J Anim Ecol. 2014;84:49-59.

21. Wang Y, Allen ML, Wilmers CC. Mesopredator spatial and temporal responses to large predators and human development in the Santa Cruz Mountains of California. Biol Conserv Elsevier Ltd. 2015;190:23-33.

22. Morrison JC, Sechrest W, Dinerstein E, Wilcove DS, Lamoreux JF. Persistence of large mammal faunas as indicators of global human impacts. J Mammal. 2007;88:1363-80.

23. Ripple WJ, Estes JA, Beschta RL, Wilmers CC, Ritchie EG, Hebblewhite $\mathrm{M}$, et al. Status and ecological effects of the world's largest carnivores. Science. 2014;343:151-63. https://doi.org/10.1126/science.1241484.

24. Di Minin E, Slotow R, Hunter LTB, Montesino Pouzols F, Toivonen T, Verburg PH, et al. Global priorities for national carnivore conservation under land use change. Sci Rep. 2016:6:1-9.

25. Berger-Tal O, Polak T, Oron A, Lubin Y, Kotler BP, Saltz D. Integrating animal behavior and conservation biology: a conceptual framework. Behav Ecol. 2011;22:236-9. https://doi.org/10.1093/beheco/arq224.

26. Wilmers CC, Wang Y, Nickel B, Houghtaling P, Shakeri Y, Allen ML, et al. Scale dependent behavioral responses to human development by a large predator, the puma. PLoS ONE. 2013;8:e60590.

27. Laundré JW. How large predators manage the cost of hunting. Science. 2014;346:33-4. https://doi.org/10.1126/science.1260170.

28. Williams TM, Wolfe L, Davis T, Kendall T, Richter B, Wang Y, et al. Instantaneous energetics of puma kills reveal advantage of felid sneak attacks. Science. 2014;346:81-5. https://doi.org/10.1126/science.1254885.

29. Wilmers CC, Crabtree RL, Smith DW, Murphy KM, Getz WM. Facilitation by introduced trophic top predators: grey wolf in Yellowstone National Park subsidies to scavengers. J Anim Ecol. 2003;72:909-16.

30. Mech LD, Smith DW, Macnulty DR, editors. Wolves on the hunt. Chicago: University of Chicago Press; 2015.

31. Mech LD. The Wolf: The Behavior and Ecology of an Endangered Species. New York: Natural History Press; 1970.

32. James ARC, Stuart-Smith AK. Distribution of caribou and wolves in relation to linear corridors. J Wildl Manage. 2000;64:154-9.

33. Whittington J, St. Clair CC, Mercer G. Spatial responses of wolves to roads and trails in mountain valleys. Ecol Appl. 2005;15:543-53.

34. Latham ADM, Latham MC, Boyce MS, Boutin S. Movement responses by wolves to industrial linear features and their effect on woodland caribou in northeastern Alberta. Ecol Appl. 2011;21:2854-65.

35. Dickie M, Serrouya R, McNay RS, Boutin S. Faster and farther: wolf movement on linear features and implications for hunting behaviour. J Appl Ecol. 2016;54:253-63. https://doi.org/10.1111/1365-2664.12732.

36. Mech LD, Korb M. An unusually long pursuit of a deer by a wolf. J Mammal. 1978;59:860-1.
37. Mech LD Cluff HD Movements of wolves at the northern extreme of the species' range, including during four months of darkness. PLOS ONE. 2011;6:e25328. https://doi.org/10.1371/journal.pone.0025328.

38. Peterson RO, Allen DL. Snow conditions as a parameter in moose-wolf relationships. Nat Can. 1974:101:481-92.

39. Huggard DJ. Effect of snow depth on predation and scavenging by gray wolves. J Wildl Manage. 1993;57:382-8.

40. Thurber JM, Peterson RO. Effects of population density and pack size on the foraging ecology of gray wolves. J Mammology. 1993;74:879-89.

41. Dale BW, Adams LG, Bowyer RT. Functional response of wolves preying on barren-ground caribou in a multiple-prey ecosystem. J Anim Ecol. 1994;63:644-52.

42. Hayes RD, Baer AM, Wotschikowsky U, Harestad AS. Kill rate by wolves on moose in the Yukon. Can J Zool. 2000;78:49-59.

43. Bieniek PA, Walsh JE, Thoman RL, Bhatt US. Using climate divisions to analyze variations and trends in Alaska temperature and precipitation. J Clim. 2014;27:2800-18.

44. Markon C, Gray S, Berman M, Eerkes-Medrano L, Hennessy T, Huntington HP, et al. Alaska. In: Reidmiller DR, Avery CW, Easterling DR, Kunkel KE, Lewis KLM, May-cock TK, et al., editors. Impacts, Risks, Adapt United States Fourth Natl Clim Assessment, Vol II. Washington, DC; 2018. p. 1185-241. https://nca2018.globalchange.gov/chapter/ $26 /$.

45. Wendler G, Gordon T, Stuefer M. On the precipitation and precipitation change in Alaska. Atmosphere (Basel). 2017:8:253.

46. Głowaciński Z, Profus P. Potential impact of wolves Canis lupus on prey populations in eastern Poland. Biol Conserv. 1997;3207:99-106.

47. Stahler DR, Smith DW, Guernsey DS. Foraging and feeding ecology of the gray wolf (Canis lupus): lessons from Yellowstone National Park, Wyoming, USA. J Nutr. 2006;136:1923S-1926S.

48. Metz MC, Smith DW, Vucetich JA, Stahler DR, Peterson RO. Seasonal patterns of predation for gray wolves in the multi-prey system of Yellowstone National Park. J Anim Ecol. 2012;81:553-63.

49. Halsey LG, Bryce CM. Proxy problems: Why a calibration is essential for interpreting quantified changes in energy expenditure from biologging data. Funct Ecol. 2021;35:627-34. https://doi.org/10.1111/ 1365-2435.13749.

50. Sand H, Wikenros $C$, Wabakken $\mathrm{P}$, Liberg O. Effects of hunting group size, snow depth and age on the success of wolves hunting moose. Anim Behav. 2006;72:781-9.

51. MacNulty DR, Smith DW, Mech LD, Vucetich J, Packer C. Nonlinear effects of group size on the success of wolves hunting elk. Behav Ecol. 2012;23:75-82. https://doi.org/10.1093/beheco/arr159.

52. Cassidy KA, MacNulty DR, Stahler DR, Smith DW, Mech LD. Group composition effects on aggressive interpack interactions of gray wolves in Yellowstone National Park. Behav Ecol. 2015;26:1352-60.

53. Peterson RO, Jacobs AK, Drummer TD, Mech LD, Smith DW. Leadership behavior in relation to dominance and reproductive status in gray wolves. Canis lupus Can J Zool. 2002:80:1405-12.

54. MacNulty DR, Smith DW, Mech LD, Eberly LE. Body size and predatory performance in wolves: is bigger better? J Anim Ecol. 2009;78:532-9.

55. Mech LD. Alpha status, dominance, and division of labor in wolf packs. Can J Zool. 1999:77:1196-203.

56. Mech LD, Boitani L. Wolf Social Ecology. In: Mech LD, Boitani L, editors. Wolves Behav Ecol Conserv. University of Chicago Press; 2003. p. $1-34$.

57. Borg BL, Brainerd SM, Meier TJ, Prugh LR. Impacts of breeder loss on social structure, reproduction and population growth in a social canid. J Anim Ecol. 2015;84:177-87.

58. Peterson RO, Ciucci P. The wolf as a carnivore. In: Mech LD, Boitani L, editors. Wolves Behav Ecol Conserv. University of Chicago Press; 2003. p. 104-30.

59. Taylor CR, Heglund NC, Maloiy GM. Energetics and mechanics of terrestrial locomotion 1. Metabolic energy consumption as a function of speed and body size in birds and mammals. J Exp Biol. 1982;97:1-21.

60. Weibel ER, Richard Taylor C, O'Neil JJ, Leith DE, Gehr P, Hoppeler H, et al. Maximal oxygen consumption and pulmonary diffusing capacity: a direct comparison of physiologic and morphometric measurements in canids. Respir Physiol. 1983;54:173-88.

61. Dunford CE, Marks NJ, Wilmers CC, Bryce CM, Nickel B, Wolfe LL, et al. Surviving in steep terrain: a lab-to-field assessment of locomotor costs 
for wild mountain lions (Puma concolor). Mov Ecol. 2020;8:34. https:// doi.org/10.1186/s40462-020-00215-9.

62. Mech LD, Adams LG, Meier TJ, Burch JW, Dale BW. The wolves of denali. Minneapolis: University of Minnesota Press; 1998.

63. Tatler J, Currie SE, Cassey P, Scharf AK, Roshier DA, Prowse TAA. Accelerometer informed time-energy budgets reveal the importance of temperature to the activity of a wild, arid zone canid. Mov Ecol. 2021;9:11. https://doi.org/10.1186/s40462-021-00246-w.

64. Rabaiotti D, Woodroffe R. Coping with climate change: limited behavioral responses to hot weather in a tropical carnivore. Oecologia. 2019;189:587-99. https://doi.org/10.1007/s00442-018-04329-1.

65. Kreeger TJ, Mech LD. The internal wolf: Physiology, pathology \& pharmacology. In: Boitani L, editor. Wolves Behav Ecol Conserv. Chicago: University of Chicago Press; 2003. p. 192-217.

66. Theuerkauf J. What drives wolves: fear or hunger? Humans, diet, climate and wolf activity patterns. Ethology. 2009;115:649-57. https://doi.org/ 10.1111/j.1439-0310.2009.01653.x.

67. Daan S, Masman D, Groenewold A. Avian basal metabolic rates: their association with body composition and energy expenditure in nature. Am J Physiol Integr Comp Physiol. 1990;259:R333-40. https://doi.org/ 10.1152/ajpregu.1990.259.2.R333.

68. Speakman JR, Thomas MD. Physiological ecology and energetics of bats. In: Kunz TH, Fenton MB, editors. Bat Biol. University of Chicago Press; 2003. p. 430-90.

69. Careau V, Morand-Ferron J, Thomas D. Basal metabolic rate of Canidae from hot deserts to cold arctic climates. J Mammal. 2007;88:394-400. https://doi.org/10.1644/06-MAMM-A-111R1.1.

70. Pagano AM, Williams TM. Estimating the energy expenditure of freeranging polar bears using tri-axial accelerometers: a validation with doubly labeled water. Ecol Evol. 2019;9:4210-9. https://doi.org/10.1002/ ece3.5053.

71. Hooge BP, Adema G, Meier T, Roland C, Brease P, Sousanes P, et al. Ecological overview of Denali National Park and Preserve. Alaska Park Sci. 2006;5:6-13.

72. Ditmer MA, Moen RA, Windels SK, Forester JD, Ness TE, Harris TR. Moose at their bioclimatic edge alter their behavior based on weather, landscape, and predators. Curr Zool. 2018;64:419-32.

73. Renecker LA, Hudson RJ. Seasonal energy expenditures and thermoregulatory responses of moose. Can J Zool. 1986;64:322-7.

74. Street GM, Rodgers AR, Fryxell JM. Mid-day temperature variation influences seasonal habitat selection by moose. JWildl Manage. 2015:79:505-12. https://doi.org/10.1002/jwmg.859.

75. Mörschel FM, Klein DR. Effects of weather and parasitic insects on behavior and group dynamics of caribou of the Delta Herd. Alaska Can J Zool. 1997;75:1659-70.

76. Russell DE, Gunn A, Kutz S. Migratory Tundra Caribou and Wild Reindeer. NOAA Arct Rep Card. 2018. p. 67-73.

77. Muñoz AR, Márquez AL, Real R. An approach to consider behavioral plasticity as a source of uncertainty when forecasting species' response to climate change. Ecol Evol. 2015;5:2359-73.

78. Noonan MJ, Newman C, Markham A, Bilham K, Buesching CD, Macdonald DW. In situ behavioral plasticity as compensation for weather variability: implications for future climate change. Clim Change. 2018;149:457-71. https://doi.org/10.1007/s10584-018-2248-5.

79. Sousanes P. Snow surveys in Denali. US National Park Service; 2016. https://www.nps.gov/articles/denali-crp-snow-surveys.htm.

80. Saperstein L. Winter forage selection by barren-ground caribou: effects of fire and snow. Rangifer. 1996;16:237.

81. Lundmark C, Ball JP. Living in snowy environments: quantifying the influence of snow on moose behavior. Arctic, Antarct Alp Res. 2008:40:111-8.

82. Droghini A, Boutin S. The calm during the storm: snowfall events decrease the movement rates of grey wolves (Canis lupus). PLoS ONE. 2018;13:1-15. https://doi.org/10.1371/journal.pone.0205742.

83. Telfer ES, Kelsall JP. Adaptation of some large North American mammals for survival in snow. Ecology. 1984:65:1828-34.

84. Droghini A, Boutin S. Snow conditions influence grey wolf (Canis lupus) travel paths: the effect of human-created linear features. Can J Zool. 2018:96:39-47.

85. Central Alaska Network. Weather \& Climate Summary: Denali National Park \& Preserve Winter 2014-Fall 2015. 2015.
86. Fancy SG, White RG. Energy expenditures for locomotion by barrenground caribou. Can J Zool. 1987;65:122-8.

87. Shepard ELC, Wilson RP, Rees WG, Grundy E, Lambertucci S, Vosper SB. Energy landscapes shape animal movement ecology. Am Nat. 2013:182:298-312.

88. Wilson RP, Quintana F, Hobson VJ. Construction of energy landscapes can clarify the movement and distribution of foraging animals. Proc $\mathrm{R}$ Soc B Biol Sci. 2012;279:975-80.

89. Halsey LG. Terrestrial movement energetics: current knowledge and its application to the optimising animal. J Exp Biol. 2016;219:1424-31. https://doi.org/10.1242/jeb.133256.

90. Pagano AM, Atwood TC, Durner GM, Williams TM. The seasonal energetic landscape of an apex marine carnivore, the polar bear. Ecology. 2020;101:1-16. https://doi.org/10.1002/ecy.2959.

91. Nickel BA, Suraci JP, Nisi AC, Wilmers CC. Energetics and fear of humans constrain the spatial ecology of pumas. Proc Natl Acad Sci. 2021;118: e2004592118. https://doi.org/10.1073/pnas.2004592118.

92. Nisi AC, Suraci JP, Ranc N, Frank LG, Oriol-Cotterill A, Ekwanga S, et al. Temporal scale of habitat selection for large carnivores: balancing energetics, risk and finding prey. J Anim Ecol. 2021. https://doi.org/10. 1111/1365-2656.13613.

93. Singleton PH, Gaines WL, Lehmkuhl JF. Landscape permeability for large carnivores in Washington: a Geographic Information System weighteddistance and least-cost corridor assessment. Portland, OR; 2002. https:// books.google.com/books?hl=en\&lr=\&id=yl64KX-TrFcC\&oi=fnd\&pg = PA1\&dq=singleton + weighted + distances\&ots $=$ DE6hhJtVYN\&sig $=$ R43DfJY-jMZcU4lz_IO98VidM2U\#v=onepage\&q=singletonweight eddistances\&f=false.

94. LaPoint S, Gallery P, Wikelski M, Kays R. Animal behavior, cost-based corridor models, and real corridors. Landsc Ecol. 2013;28:1615-30. https:// doi.org/10.1007/s10980-013-9910-0.

95. Halsey $L G$, White CR. A different angle: comparative analyses of wholeanimal transport costs running uphill. J Exp Biol. 2016;220:161.

96. Reichman OJ, Aitchinson S. Mammal trails on mountain slopes: optimal paths in relation to slope angle and body weight. Am Nat. 1981:117:416-20.

97. Nathan R, Getz WM, Revilla E, Holyoak M, Kadmon R, Saltz D, et al. A movement ecology paradigm for unifying organismal movement research. Proc Natl Acad Sci. 2008;105:19052-9.

98. Morales JM, Moorcroft PR, Matthiopoulos J, Frair JL, Kie JG, Powell R, et al. Building the bridge between animal movement and population dynamics. Philos Trans R Soc Lond B Biol Sci. 2010;365:2289-301.

99. Nagy K. Field bioenergetics of mammals: what determines field metabolic rates? Aust J Zool. 1994:42:43-53.

100. Eggermann J, Gula R, Pirga B, Theuerkauf J, Tsunoda H, Brzezowska $B$, et al. Daily and seasonal variation in wolf activity in the Bieszczady Mountains. SE Poland Mamm Biol. 2009;74:159-63.

101. Theuerkauf J, Jędrzejewski W, Schmidt K, Okarma H, Ruczyński I, Śnieżko $S$, et al. Daily patterns and duration of wolf activity in the Białowieża Forest. Poland J Mammal. 2003;84:243-53. https://doi.org/10.1644/ 1545-1542(2003)084\%3C0243:DPADOW\%3E2.0.CO;2.

102. Nagy KA, Girard IA, Brown TK. Energetics of free ranging mammals, reptiles, and birds. Annu Rev Nutr. 1999:19:247-77.

103. Petroelje TR, Belant JL, Beyer DE, Svoboda NJ. Identification of carnivore kill sites is improved by verified accelerometer data. Anim Biotelemetry. 2020;8:18. https://doi.org/10.1186/s40317-020-00206-y.

104. Hooten MB, Scharf HR, Morales JM. Running on empty: recharge dynamics from animal movement data. Ecol Lett. 2018;22:377-89.

105. Latombe G, Parrott L, Basille M, Fortin D. Uniting statistical and individual-based approaches for animal movement modelling. PLoS ONE. 2014;9:e99938. https://doi.org/10.1371/journal.pone.0099938.

106. D'Eon RG, Serrouya R, Smith G, Kochanny CO. GPS radiotelemetry error and bias in mountainous terrain. Wildl Soc Bull. 2002;30:430-9.

107. Brown DD, LaPoint S, Kays R, Heidrich W, Kummeth F, Wikelski M. Accelerometer-informed GPS telemetry: reducing the trade-off between resolution and longevity. Wildl Soc Bull. 2012;36:139-136.

108. Brown DD, Kays R, Wikelski M, Wilson R, Klimley A. Observing the unwatchable through acceleration logging of animal behavior. Anim Biotelemetry. 2013;1:1.

109. Wilson RP, White CR, Quintana F, Halsey LG, Liebsch N, Martin GR, et al. Moving towards acceleration for estimates of activity-specific 
metabolic rate in free-living animals: the case of the cormorant. J Anim Ecol. 2006;75:1081-90.

110. Wilmers CC, Isbell LA, Saraci JP, Williams TM. Energetics-informed behavioral states reveal the drive to kill in African leopards. Ecosphere. 2017:8:1-12.

111. Bryce CM, Wilmers CC, Williams TM. Energetics and evasion dynamics of large predators and prey: pumas vs. hounds. PeerJ. 2017:5:1-23.

112. Williams TM, Blackwell SB, Richter B, Sinding MS, Heide-Jørgensen MP. Paradoxical escape responses by narwhals (Monodon monoceros). Science. 2017;358:1328-31. https://doi.org/10.1126/science.aao2740.

113. Bowyer T, Person DK, Becky MP. Detecting top-down versus bottom-up regulation of ungulates by large carnivores: Implications for conservation of biodiversity. In: Ray JC, Redford KH, Steneck RS, Berger J, editors. Large Carniv Conserv Biodivers. 2005. p. 342-61.

114. Ripple WJ, Beschta RL. Large predators limit herbivore densities in northern forest ecosystems. Eur J Wildl Res. 2012;58:733-42. https://doi. org/10.1007/s10344-012-0623-5.

115. Carroll C, Rohlf DJ, VonHoldt BM, Treves A, Hendricks SA. Wolf delisting challenges demonstrate need for an improved framework for conserving intraspecific variation under the Endangered Species Act. Bioscience. 2020;71:73-84. https://doi.org/10.1093/biosci/biaa125/5941853.

116. Gleiss AC, Wilson RP, Shepard ELC. Making overall dynamic body acceleration work: on the theory of acceleration as a proxy for energy expenditure. Methods Ecol Evol. 2011;2:23-33. https://doi.org/10. 1111/j.2041-210X.2010.00057.x.

117. Qasem L, Cardew A, Wilson A, Griffiths I, Halsey LG, Shepard ELC, et al. Tri-axial dynamic acceleration as a proxy for animal energy expenditure; should we be summing values or calculating the vector? PLOS ONE. 2012;7:e31187.

118. Bidder OR, Qasem L, Wilson RP. On higher ground: how well can dynamic body acceleration determine speed in variable terrain? PLoS ONE. 2012;7:1-7.

119. Raab JL, Eng P, Waschler RA. Metabolic cost of grade running in dogs. J Appl Physiol. 1976;41:532-5.

120. Carnahan AM, van Manen FT, Haroldson MA, Stenhouse GB, Robbins $\mathrm{CT}$. Quantifying energetic costs and defining energy landscapes experienced by grizzly bears. J Exp Biol. 2021;224:1-9.

121. Meier TJ, Burch JW. Wolf monitoring protocol for Denali National Park and Preserve, Yukon-Charley Rivers National Preserve and Wrangell-St. Elias National Park and Preserve. Fort Collins, CO; 2009.

122. Meier TJ, Burch JW, Adams LG. Tracking the movement of Denali's wolves. Alaska Park Sci. 2006:5:30-5.

123. Johnson DS, London JM. crawl: an R package for fitting continuoustime correlated random walk models to animal movement data. Zenodo. 2018. https://cran.r-project.org/web/packages/crawl/crawl. pdf.

124. Johnson DS, London JM, Lea MA, Durban JW. Continuous-time correlated random walk model for animal telemetry data. Ecology. 2008:89:1208-15.

125. Calabrese JM, Fleming CH, Gurarie E. ctmm: an R package for analyzing animal relocation data as a continuous-time stochastic process. Methods Ecol Evol. 2016;7:1124-32. https://doi.org/10.1111/2041-210X. 12559.

126. Schmidt-Nielsen K. Animal physiology: adaptation and environment. 5th ed. Cambridge: Cambridge University Press; 1997.

127. R Foundation for Statistical Computing. R: a language and environment for statistical computing. 2020. http://www.r-project.org/

128. Fox J, Weisberg S. An R Companion to Applied Regression. SAGE Publications; 2019.

129. Bartoń K. Package "MuMIn": Multi-Model Inference. 2020. p. 75.

130. Bates D, Mächler M, Bolker B, Walker S. Fitting linear mixed-effects models using Ime4. J Stat Softw. 2015;67. http://www.jstatsoft.org/v67/ i01/

131. Lenth RV, Buerkner P, Herve M, Love J, Riebl H, Singmann H. Package 'emmeans': Estimated Marginal Means, aka Least-Squares Means. 2021. https://github.com/rvlenth/emmeans

132. Peterson RA. Package 'bestNormalize": Normalizing Transformation Functions'. 2021 https://github.com/petersonR/bestNormalize.

133. Powell M. The BOBYQA algorithm for bound constrained optimization without derivatives. NA Rep NA2009/06. 2009:39.
134. Wood SN. Fast stable restricted maximum likelihood and marginal likelihood estimation of semiparametric generalized linear models. J R Stat Soc Ser B. 2011;73:3-36. https://doi.org/10.1111/j.1467-9868.2010. 00749.x.

\section{Publisher's Note}

Springer Nature remains neutral with regard to jurisdictional claims in published maps and institutional affiliations.
Ready to submit your research? Choose BMC and benefit from:

- fast, convenient online submission

- thorough peer review by experienced researchers in your field

- rapid publication on acceptance

- support for research data, including large and complex data types

- gold Open Access which fosters wider collaboration and increased citations

- maximum visibility for your research: over $100 \mathrm{M}$ website views per year

At BMC, research is always in progress.

Learn more biomedcentral.com/submissions 